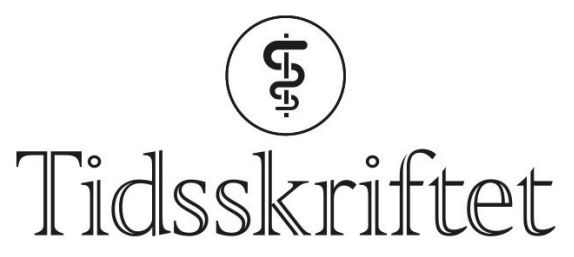

DEN NORSKE LEGEFORENING

\title{
Legemiddelavvik hos pasienter innlagt i sykehus
}

\author{
ORIGINALARTIKKEL \\ HANNE SKEIE* \\ Institutt for klinisk og molekylær medisin \\ NTNU \\ og \\ Avdeling for klinisk farmakologi \\ St. Olavs hospital \\ Hun har bidratt med utforming/design, datainnsamling, analyse og tolkning av data, \\ utarbeiding/revisjon av manuset og godkjenning av innsendte manusversjon. \\ Hanne Skeie er lege i spesialisering del 1 ved Voss sjukehus. \\ Forfatteren har fylt ut ICMJE-skjemaet og oppgir ingen interessekonflikter.

\section{RAGNHILD NORDLUND*} \\ Institutt for klinisk og molekylær medisin \\ NTNU \\ og \\ Avdeling for klinisk farmakologi \\ St. Olavs hospital \\ Hun har bidratt med utforming/design, datainnsamling, analyse og tolkning av data, \\ utarbeiding/revisjon av manuset og godkjenning av innsendte manusversjon. \\ Ragnhild Nordlund er lege i Stavanger kommune \\ Forfatteren har fylt ut ICMJE-skjemaet og oppgir ingen interessekonflikter.
}

\section{LARS SLØRDAL}

Institutt for klinisk og molekylær medisin

NTNU

og

Avdeling for klinisk farmakologi

St. Olavs hospital

Han har bidratt med idé, utforming/design, analyse og tolkning av data, utarbeiding/revisjon av manuset og godkjenning av innsendte manusversjon.

Lars Slørdal er dr.med., spesialist i klinisk farmakologi, professor og overlege.

Forfatteren har fylt ut ICMJE-skjemaet og oppgir ingen interessekonflikter.

\section{OLAV SPIGSET}

E-post: olav.spigset@legemidler.no Institutt for klinisk og molekylær medisin NTNU

og

Avdeling for klinisk farmakologi

St. Olavs hospital

Han har bidratt med idé, utforming/design, datainnsamling, analyse og tolkning av data,

utarbeiding/revisjon av manuset og godkjenning av innsendte manusversjon.

Olav Spigset er dr.med., spesialist i klinisk farmakologi, overlege og professor. 


\section{BAKGRUNN}

Avvik i bruk og håndtering av legemidler er ikke uvanlig. Det finnes lite oppdatert informasjon om legemiddelavvik i norske sykehus.

\section{MATERIALE OG METODE}

Alle uønskede hendelser ved St. Olavs hospital er pålagt intern meldeplikt via et elektronisk skjema. Vi har for treårsperioden 2015-17 systematisert registrerte legemiddelavvik i databasen der rapportene lagres, og sammenlignet med tall fra en tilsvarende studie gjennomført i årene 2002-06.

\section{RESULTATER}

Totalt 1604 legemiddelavvik ble registrert, fordelt på 1587 meldinger. Doseringsavvik dominerte ( $n=1070 ; 67 \%)$, etterfulgt av at det hadde blitt gitt et annet legemiddel enn ordinert $(n=175 ; 11 \%)$. Majoriteten var av ubetydelig eller lav alvorlighetsgrad. Det var en overhyppighet av rapportering blant de yngste og de eldste pasientene. $79 \%$ av avvikene ble meldt av sykepleiere. Uoppmerksomhet/forglemmelse (15\%), stress/travelhet (12\%), slurvete kurveføring (10\%) og feil/uklar ordinering (10\%) ble oppgitt som de vanligste årsakene.

\section{FORTOLKNING}

Antallet meldinger om legemiddelavvik er økende, men det er usikkert hvor store mørketallene er. Avvikstypene og fordelingen mellom dem er den samme som i tidligere studier. De underliggende årsakene er også velkjente. Utfordringen ligger i å hindre at slike forhold oppstår.

Legemiddelavvik (medication errors) forekommer i alle ledd i helsetjenesten. I sykehus kan avvik skje både i forbindelse med ordinering, istandgjøring (dispensering) og utdeling (administrering) av legemidler. Både nasjonalt og internasjonalt er forebygging av legemiddelavvik et prioritert område $(1,2)$.

Avhengig av hvordan begrepet er definert og studiene utført, vil forekomsten av legemiddelavvik i sykehus variere $(3,4)$. I systematiske oversiktsartikler er det rapportert om avvik ved gjennomsnittlig $7 \%$ av alle ordineringer (3) og inntil $20 \%$ av tilfellene av istandgjøring og utdeling av legemidler (4). De vanligst rapporterte avvikene er at legemidlene er gitt på feil tidspunkt, ikke er gitt eller er gitt i feil dose (4).

Frem til 2019 hadde sykehusene etter § 3-3 i spesialisthelsetjenesteloven plikt til å melde hendelser som hadde eller kunne ha ført til betydelig personskade til den nasjonale meldeordningen. Avvikene ble rapportert uten risiko for sanksjoner. En gjennomgang av 3 372 legemiddelavvik som ble rapportert til meldeordningen i 2016 og 2017 (5), viste at 68 \% av avvikene forekom ved utdeling, $24 \%$ ved ordinering og $6 \%$ ved istandgjøring. De vanligste avvikstypene var doseavvik (38\%), glemt legemiddel (23\%) og feil legemiddel (15\%). Utfallet var klassifisert som «alvorlig» hos 177 pasienter (5,2\%) og som «død» hos 27 pasienter (o,8\%). Basert på meldingene til meldeordningen utarbeidet først Kunnskapssenteret og senere Helsedirektoratet årsrapporter og læringsnotater som beskrev slike uheldige hendelser. Ordningen ble avviklet 15.5.2019 (6).

Alle virksomheter som yter helse- og omsorgstjenester, har nå plikt til å melde alvorlige hendelser til Helsetilsynet (7). Utover dette er det lovfestet at spesialisthelsetjenesten skal ha egne rutiner for kvalitetsforbedring og pasientsikkerhetsarbeid (8). I sykehus inkluderer 
dette også intern avviksrapportering av mindre alvorlige hendelser.

Vi har tidligere publisert en studie av innrapporterte legemiddelavvik ved St. Olavs hospital i perioden 1.7.2002-30.6.2006 (9). Målet med denne oppfølgingsstudien er å beskrive utvikling og status på dette området.

\section{Materiale og metode}

Denne studien omhandler legemiddelrelaterte avvik som ble rapportert ved St. Olavs hospital i treårsperioden 1.1.2015-31.12.2017. Ifølge sykehusets prosedyrer skal alle uønskede hendelser meldes på et elektronisk meldeskjema (appendiks 1). Dataene lagres i en sentral database på sykehuset. Informasjon som ble hentet ut fra hvert skjema i denne databasen omfattet bl.a. pasientens kjønn og fødselsår, melderens yrke, type hendelse, beskrivelse av hendelsen, angitt årsak og forslag til tiltak. Kun meldinger som melderen selv hadde klassifisert som «legemiddelavvik» i et eget avkryssingsfelt, ble inkludert. Informasjon om totalt antall årsverk for ansatte og antall liggedøgn ved sykehuset i den aktuelle perioden ble innhentet fra økonomiavdelingen.

Studieprotokollen ble sendt til Regional komité for medisinsk og helsefaglig forskningsetikk i Midt-Norge, som vurderte prosjektet som kvalitetssikring som kunne gjennomføres uten forhåndsgodkjenning (referansenummer 2017/1229). Prosjektet ble også meldt til Norsk senter for forskningsdata (NSD), som på den tiden fungerte som personvernombud for St. Olavs hospital. De konkluderte med at prosjektet oppfylte de aktuelle lovkravene (referansenummer 57502).

I tillegg til situasjonsbeskrivelsen av den aktuelle inklusjonsperioden har vi sammenlignet med tall fra den tilsvarende undersøkelsen fra perioden 2002-06 (9).

\section{Resultater}

I den aktuelle treårsperioden var det registrert 1808 meldinger klassifisert som legemiddelavvik. I alt 221 av disse ble ekskludert, fordi de var behandlingsavvik uten å involvere legemidler $(n=84)$, omhandlet avvik før innleggelsestidspunktet $(n=30)$, omhandlet feil på teknisk utstyr $(n=26)$, representerte bivirkninger og ikke avvik $(n=14)$ eller skyldtes andre forhold $(n=67)$. Totalt ble dermed 1587 meldinger inkludert $i$ analysen. Siden 17 meldinger inneholdt to avvik, var totalt antall avvik 1604 .

I 2015, 2016 og 2017 ble det rapportert henholdsvis 516, 491 og 580 legemiddelavvik. Dette utgjorde o,83, 0,78 og o,9o meldinger per 100 årsverk ved sykehuset. Av de 1240 rapportene der melders yrke var angitt, var 985 (79\%) meldt av sykepleiere, 86 (7\%) av kvalitetsrådgivere, 47 (4\%) av leger og $122(10 \%)$ av annet personell.

Avvikene rammet $51 \%$ menn og $49 \%$ kvinner. Pasientenes aldersfordeling er vist i figur 1 . I tabell 1 presenteres de ulike typene avvik sammenlignet med tilsvarende tall fra perioden 2002-06. Det vanligste var avvik i dosering, som ble meldt i 1 070/1 604 tilfeller (67\%), fordelt på doseavvik (51\%), tidsavvik (12\%) og hastighetsavvik (3\%). Doseavvikene er nærmere spesifisert i tabell 2. 


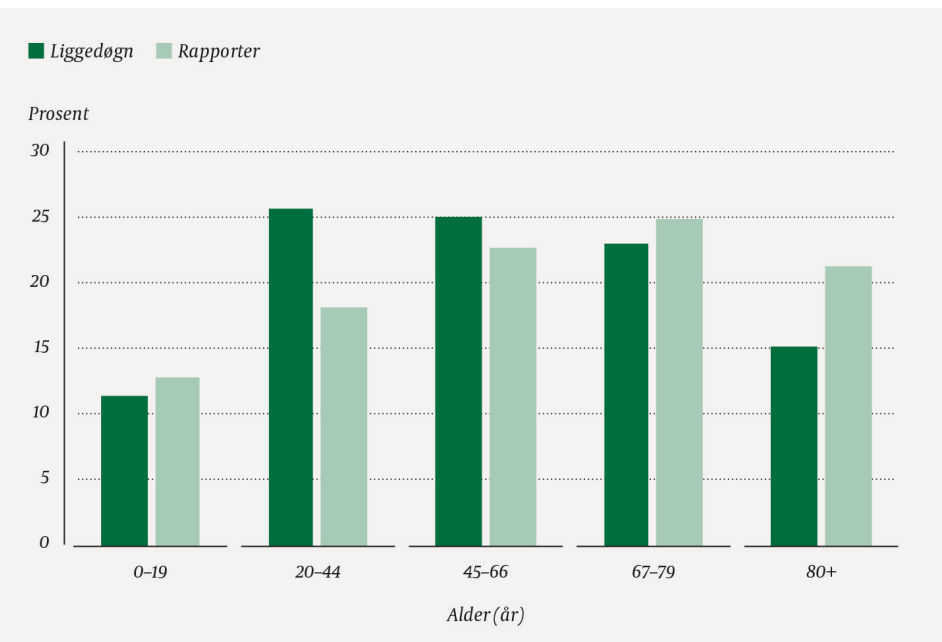

Figur 1 Prosentvis andel rapporter fordelt etter aldersgrupper og sammenlignet med andel liggedøgn $i$ de samme aldersgruppene i den samme perioden. Inndelingen på $x$-aksen er gjort ut fra de aldersintervallene som var tilgjengelige. Observer at disse intervallene har ulik lengde.

\section{Tabell 1}

Oversikt over typer legemiddelavvik rapportert ved St. Olavs hospital i perioden 1.1.2015-31.12.2017 sammenlignet med en tilsvarende studie fra perioden 1.7.2002-30.6.2006 (9).

\begin{tabular}{|c|c|c|}
\hline \multirow{2}{*}{$\begin{array}{l}\text { Type avvik } \\
\text { Doseringsavvik }\end{array}$} & \multicolumn{2}{|c|}{ Antall (\%), 2015-17 Antall (\%), 2002-06 } \\
\hline & $1070(67)$ & $309(51)$ \\
\hline Doseavvik & $826(51)$ & $237(39)$ \\
\hline Tidsavvik $^{2}$ & $196(12)$ & $37(6)$ \\
\hline Hastighetsavvik $^{3}$ & $48(3)$ & $35(6)$ \\
\hline Administreringsavvik & $144(9)$ & $111(18)$ \\
\hline Intravenøs infusjon gått subkutant & $110(7)$ & $92(15)$ \\
\hline Annen administreringsmåte enn ordinert ${ }^{4}$ & $30(2)$ & $19(3)$ \\
\hline Gitt annet legemiddel enn ordinert & $175(11)$ & $104(17)$ \\
\hline Legemidlet gitt til en annen pasient & $76(5)$ & $75(12)$ \\
\hline Legemidlet utgått på dato & $15(1)$ & $7(1)$ \\
\hline Legemidlet kontraindisert hos pasienten $^{5}$ & $20(1)$ & $4(1)$ \\
\hline Dokumentasjonsavvik $^{6}$ & $101(6)$ & $0(0)$ \\
\hline Annet & $3(0,2)$ & $0(0)$ \\
\hline Totalt & $1604(100)$ & $610(100)$ \\
\hline
\end{tabular}

${ }^{1}$ For detaljer se tabell 2

${ }^{2}$ Pasienten har fått riktig legemiddel i riktig mengde, men til en annen tid enn det som var angitt

${ }^{3}$ Pasienten har fått riktig legemiddel i riktig totalmengde, men legemidlet ble gitt intravenøst med avvikende hastighet

${ }^{4}$ Peroralt i stedet for rektalt, i perifer vene i stedet for i sentralt venekateter, i perifer vene i stedet for i ventrikkelsonde, intravenøst i stedet for intramuskulært etc.

${ }^{5}$ hovedsak at det var angitt i journalen at pasienten var allergisk/overfølsom mot det midlet som ble gitt

${ }^{6}$ I hovedsak manglende signering for utdeling av gitt legemiddel eller manglende dobbeltsignering i situasjoner der dette ifølge sykehusets prosedyrer er påkrevet. Det ble ikke meldt slike avvik i perioden 2002-06, noe som trolig kan tilskrives at legemiddelhåndteringsforskriften kom i 2008 (13). 
Tabell 2

Oversikt over typer doseavvik rapportert ved St. Olavs hospital i perioden 1.1.2015-31.12.2017 sammenlignet med en identisk studie fra perioden 1.7.2002-30.6.2006 (9).

\begin{tabular}{|lrr|}
\hline Type doseavvik & Antall (\%), 2015-17 Antall (\%), 2002-06 \\
\hline Gitt for høy dose & $350(22)$ & $159(26)$ \\
\hline Gitt for lav dose & $65(4)$ & $37(6)$ \\
\hline Avglemt dose & $334(21)$ & $35(6)$ \\
\hline Gitt etter seponering & $37(2)$ & $4(0,7)$ \\
\hline Forvekslet mg og ml & $3(0,2)$ & $2(0,3)$ \\
\hline Uklart angitt & $37(2)$ & $0(0)$ \\
\hline Totalt & $826(51)$ & $237(39)$ \\
\hline
\end{tabular}

Alvorlighetsgraden av avvikene var angitt som ingen eller ubetydelig i 898 tilfeller (57\%), som lav i 640 tilfeller ( $40 \%$ ), som moderat i 19 tilfeller (1,2\%) og som betydelig i 5 tilfeller (o,3\%). I 19 tilfeller var utfallet angitt som ukjent (1,2 \%), mens spørsmålet ikke var besvart i 6 tilfeller $(0,4 \%)$. I 10 av de 24 tilfellene der alvorlighetsgraden var angitt som moderat eller betydelig, var årsaken at det var for gitt for høy dose. Fire av disse hendelsene gjaldt morfin.

I 921 tilfeller var det stilt spørsmål om det hadde blitt iverksatt tiltak (dette spørsmålet var ikke med i første del av registreringsperioden), og i 317 av disse var spørsmålet besvart. I $198 / 317$ tilfeller (62\%) var det angitte tiltaket enten at det var startet behandling eller at det var utført ekstra oppfølging av pasienten, for eksempel med blodprøver eller intensivert monitorering. Spørsmål om hvorvidt pasienten eller pårørende hadde blitt informert om hendelsen, ble stilt i de samme 921 tilfellene. I 901 av disse fantes det konklusiv informasjon: Svaret var «ja» i 429 tilfeller (48\%), «nei» i 306 tilfeller (34\%) og «ikke relevant» i 166 tilfeller (18\%).

Informasjon om oppføring i pasientjournal manglet i 674/1 587 tilfeller (42\%). I 614 tilfeller (39\%) ble hendelsen dokumentert i pasientjournalen, mens hendelsen forble udokumentert i 226 tilfeller (14\%). I 56 tilfeller (4\%) ble dokumentasjon i journalen vurdert som ikke relevant, og i 17 tilfeller (1\%) ble det svart «vet ikke» på spørsmålet. I kun 4/1587 tilfeller $(0,3 \%)$ var det angitt at pasienten hadde fått informasjon om Norsk pasientskadeerstatning. I de øvrige tilfellene ble spørsmålet enten ikke besvart (1 o70 meldinger, $67 \%$ ), vurdert som irrelevant (327 meldinger, $21 \%$ ) eller besvart benektende (186 meldinger, $12 \%)$.

Rapporterte årsaker til avvikene er presentert i tabell 3 .

\section{Tabell 3}

Angitt årsak til 1587 legemiddelavvik rapportert ved St. Olavs hospital i perioden 1.1.2015-31.12.2017. Siden denne informasjonen ikke ble systematisk etterspurt på skjemaet som ble brukt i perioden 1.7.2002-30.6.2006 (9), er det ikke tilgjengelige tall å sammenligne med.

\begin{tabular}{|lr|}
\hline Årsak til avvik & Antall (\%) \\
\hline Uoppmerksomhet, forglemmelse & $245(15)$ \\
\hline Stress, travelhet & $192(12)$ \\
\hline Slurvete kurveføring, feiltolkning av kurve & $166(10)$ \\
\hline Feil/uklar ordinering, manglende samstemming av dokumenter & $154(10)$ \\
\hline Feil opplegging i dosett, feil plassering på medisinrommet & $90(6)$ \\
\hline Infusjon gått subkutant, ukjent årsak & $84(5)$ \\
\hline Rutine/prosedyre ikke fulgt & $78(5)$ \\
\hline Manglende utført dobbeltkontroll & $69(4)$ \\
\hline
\end{tabular}




\begin{tabular}{|lr|}
\hline Årsak til avvik & Antall (\%) \\
\hline Annet & $276(17)$ \\
\hline Ukjent, ikke mulig å vurdere & $233(15)$ \\
\hline Totalt & $1587(100)$ \\
\hline
\end{tabular}

\section{Diskusjon}

Undersøkelsen fra 2002-o6 (9) omfattet 610 meldinger over en periode på tre år. I treårsperioden 2015-17 hadde antall meldinger $ø \mathrm{kt}$ til 1 587. En del av økningen skyldes at Divisjon psykisk helsevern og enhetene i Orkanger og Røros i mellomtiden var blitt inkludert i sykehusets sentrale meldesystem. Hvis disse unntas fra den siste unders $\emptyset$ kelsen, var antallet meldinger 1176 , noe som tilsvarer rundt en fordobling av antallet meldinger, fra omtrent 200 til 400 per år, fra den første til den andre perioden. Årsakene kan være større fokus på rapportering både nasjonalt (1) og lokalt, at meldeprosessen er blitt enklere og at det i større grad oppfordres til å rapportere avvik med lav alvorlighetsgrad. Samtidig kan vi ikke utelukke at $ø$ kningen skyldes at avviksfrekvensen $ø$ ker.

Det var en jevn kjønnsfordeling i rapportene, noe som samsvarer godt med tidligere funn (9). Også rapporteringsfrekvensen sett i forhold til alder var i prinsippet den samme i de to studiene, med flest liggedøgnkorrigerte rapporter i de yngste og eldste aldersgruppene.

I de fleste tilfellene var meldingene skrevet av sykepleiere, noe som samsvarer med resultatene fra den forrige undersøkelsen (9). Dette skyldes trolig at det forekommer størst grad av avvik ved de arbeidsoppgavene sykepleierne utfører (4). For avvik knyttet til typiske legeoppgaver som anamnese og ordinering, var 26 meldt av leger og 124 av sykepleiere. Denne skjevfordelingen kan skyldes at det er sykepleierne som fanger opp de avvikene som legene har forårsaket, men det kan også tenkes at leger i større grad enn sykepleiere lar være å rapportere avvik (10). De mest alvorlige avvikene var imidlertid i hovedsak rapportert av leger.

Våre tall stemmer relativt godt overens med resultatene fra den forrige undersøkelsen (9), og også med det som ble rapportert til meldeordningen i årene 2016-17 (5). Selv om meldeordningen har mottatt rapporter fra rundt 60 ulike sykehus og vi kun har sett på ett, var det små forskjeller i andelen rapporter mellom studiene for sentrale avviksgrupper som doseringsavvik, at det var gitt et annet legemiddel enn ordinert og at legemidlet var gitt til en annen pasient.

I $48 \%$ av meldingene med konklusive svar var det angitt at pasient og/eller pårørende hadde blitt informert om hendelsen. I og med at meldeskjemaet er blitt endret underveis i perioden, er det ikke mulig å sammenligne dette tallet med resultatene fra den forrige studien (9). I henhold til § 3-2 i lov om pasient- og brukerrettigheter har pasienten rett til informasjon dersom hendelsen medfører skade eller alvorlige komplikasjoner (11), mens det sier seg selv at det ikke har noen hensikt å informere pasienten i tilfeller hvor avviket ble oppdaget og avverget før det nådde frem til vedkommende.

Stress, travelhet og uoppmerksomhet pekte seg ut som de viktigste årsakene til avvik. Tiltak som kan begrense stress og påfølgende feil i en travel arbeidshverdag, er derfor en sentral faktor for å redusere risikoen for avvik. Mulighet til å gjøre i stand legemidler i fred og ro uten distraksjoner er ett slikt tiltak. I en skotsk studie så man redusert forekomst av legemiddelavvik etter at ansvarlig personale ble ikledd en spesiell vest som signaliserte «ikke forstyrr» (12). Et slikt tiltak er vanskeligere å gjennomføre ved primærsykepleie. Årsaker til ordineringsavvik omfattet i hovedsak manglende samstemming av legemiddellister, utydelig håndskrift og feil ved overføring til nytt kurveark. Innføring av elektronisk kurve vil redusere eller eliminere flere av forholdene rundt kurveføring.

På grunn av en iboende underrapportering (13) gir ikke avvikssystemet sikker informasjon til ledere om omfanget av legemiddelavvik på hvert enkelt sted i organisasjonen, og dermed heller ikke indikasjoner på hvor problemene er størst. Medarbeiderundersøkelser av arbeidsmiljø og pasientsikkerhetskultur er derfor en viktig del av risikokartleggingen (14, 
15). Den årlige nasjonale medarbeiderundersøkelsen i sykehus, ForBedring, som startet i 2018 og som inneholder en kategori om sikkerhetsklima (16), kan være et godt utgangspunkt for forbedringer og supplement til avvikssystemet. Det er imidlertid viktig at resultatene presenteres på lavest mulig nivå i organisasjonen, siden det vil være stor variasjon i hvordan de ansatte ved forskjellige enheter vurderer slike forhold (17).

Denne studien har en rekke svakheter. Den gir ikke informasjon om den reelle avviksforekomsten, og informasjonen er begrenset til det som fremgår av meldingene. Systematiseringen har gitt utfordringer, siden melderutinene og variablene som inngår i rapportene er blitt endret - både i løpet av studieperioden og sammenlignet med forrige studieperiode (9). Én viktig forskjell er at i forrige skjema var punktet om årsaksforhold et avkrysningsspørsmål som ble fylt ut av avdelingsledelsen. I denne undersøkelsen er det melder selv som med egne ord har beskrevet årsaken. Dette kan ha ført til at det nå i større grad pekes på arbeidsmiljø som årsak, selv om vi ikke har tall som direkte sannsynliggjør dette. Det er også relativt store forskjeller mellom skjemaene når det gjelder rapportering om hva som ble gjort i etterkant av hendelsen. Derfor er det heller ikke her mulig å sammenligne tall direkte. For nøkkelpunktene er det imidlertid så stor grad av overensstemmelse mellom skjemaene at det ikke er grunnlag for å tro at eventuelle forskjeller i resultatene mellom de to undersøkelsene kan forklares av ulik skjemautforming.

Sammenholdt viser de to studiene at det er de samme typer avvik som rapporteres nå som for 10-20 år siden. Hvilke prinsipielle typer legemiddelavvik som oppstår, er godt kjent og ser også ut til å opptre konstant over tid. Våre funn stemmer godt overens med internasjonal litteratur $(3,4)$ og en annen nyere norsk studie (5). Likevel har avviksrapportering en viktig funksjon med tanke på å identifisere avdelingsspesifikke forhold. For eksempel må endringer i rutiner for å redusere årsaker som stress og travelhet løses på hver enkelt avdeling. Andre typer kunnskap (kurveføring, utblanding av legemidler) er derimot generell og kan læres uavhengig av rapporterte hendelser på enkeltavdelinger.

I den forrige studien (9) ble det foreslått 17 enkelttiltak for å forebygge legemiddelavvik (appendiks 2). Disse punktene er fortsatt viktige, men på en del av områdene har det skjedd endringer som foreslått. Blant annet har nasjonal standardisert fargekoding blitt innført for merking av sprøyter ved anestesiprosedyrer (18). Vi har i appendiks 2 satt inn en kolonne der vi kommenterer endringer som har skjedd siden 2009-publikasjonen (9). Selv om alle foreslåtte tiltak innføres, vil imidlertid ikke alle avvik forsvinne. For eksempel har innføring av multidosepakkede legemidler ført til nye, uforutsette avvik (19). Og selv om elektroniske legemiddelkurver helt fjerner avvik som skyldes utydelig håndskrift og manuell overføring mellom kurveark, er det risiko for at nye typer avvik oppstår (20). Derfor vil det, etter hvert som organisasjon, rutiner og tekniske hjelpemidler endres, kunne bli nødvendig med nye forebyggende tiltak.

Tidligere har vi foreslått at sentrale myndigheter bør sammenstille informasjonen i rapporter som meldes inn og komme med forslag til hvordan de viktigste avvikene kan unngås (9). Den nå avviklede nasjonale meldeordningen oppfylte dette ønsket, og de læringsnotatene som ble produsert, er fortsatt tilgjengelige (21). Siden kompetansen og kapasiteten på lokalt nivå kan være utilstrekkelig, er det viktig med nasjonale systemer som kan gi informasjon om hvordan de viktigste avvikene kan unngås. Det trengs en felles innsats på enhetsnivå, sykehusnivå og nasjonalt nivå for at man skal kunne lære, ikke bare av egne feil, men også av andres. I tillegg er lokale tiltak vesentlige når det gjelder å bygge en pasientsikkerhetskultur. Vi mangler ikke kunnskap om hvilke typer legemiddelavvik som kan oppstå - utfordringen er å hindre at de oppstår. 


\section{HOVEDFUNN}

I løpet av en 15-årsperiode har det vært mer enn en fordobling av antall rapporterte legemiddelavvik ved St. Olavs hospital.

Doseringsavvik dominerte, og kun et fåtall av avvikene hadde alvorlige konsekvenser.

De fleste avvikene ble meldt av sykepleiere, og uoppmerksomhet/forglemmelse sammen med stress/travelhet dominerte som årsak.

\section{LITTERATUR:}

1. I trygge hender 24-7.

https://pasientsikkerhetsprogrammet.no/om-oss/om-pasientsikkerhetsprogrammet/i-trygge-hender-2 4-7 Lest 11.8.2020.

2. Medication without harm. WHO global patient safety challenge. Geneve: World Health

Organization, 2017.

https://www.who.int/patientsafety/medication-safety/medication-without-harm-brochure/en Lest 11.8.2020.

3. Lewis PJ, Dornan T, Taylor D et al. Prevalence, incidence and nature of prescribing errors in hospital inpatients: a systematic review. Drug Saf 2009;32:379-89. [PubMed][CrossRef]

4. Keers RN, Williams SD, Cooke J et al. Prevalence and nature of medication administration errors in health care settings: a systematic review of direct observational evidence. Ann Pharmacother 2013; 47: 237-56. [PubMed][CrossRef]

5. Mulac A, Taxis K, Hagesaether E et al. Severe and fatal medication errors in hospitals: findings from the Norwegian Incident Reporting System. Eur J Hosp Pharm Sci Pract 2020; 27:

ejhpharm-2020-002298. [PubMed][CrossRef]

6. Stortinget. Endringar i spesialisthelsetenestelova m.m.

https://www.stortinget.no/nn/Saker-og-publikasjonar/Saker/Sak/?p=73612 Lest 11.8.2020.

7. Helsetilsynet. Varsel om alvorlige hendelser i spesialisthelsetjenesten.

https://www.helsetilsynet.no/tilsyn/varsel-om-alvorlige-hendelser/varsel-om-alvorlige-hendelser-i-spe sialisthelsetjenesten Lest 11.8.2020.

8. Rundskriv IS-5/2013. Spesialisthelsetjenesteloven med kommentarer. Oslo: Helsedirektoratet, 2013. https://www.helsedirektoratet.no/rundskriv/spesialisthelsetjenesteloven-med-kommentarer/Spesialis thelsetjenesteloven-med-kommentarer-IS-5-2013.pdf Lest 11.8.2020.

9. Teigen IM, Rendum KL, Slørdal L et al. Feilmedisinering hos pasienter innlagt i sykehus. Tidsskr Nor Legeforen 2009; 129: 1337-41. [PubMed][CrossRef]

10. Paulsen PME, Bratteb $ø$ G. Medisinstudentar og legar sine haldningar til medisinske feil og pasientskade. Tidsskr Nor Lægeforen 2006; 126: 2129-32. [PubMed]

11. LOV-1999-07-02-63. Lov om pasient- og brukerrettigheter.

https://lovdata.no/dokument/NL/lov/1999-07-02-63 Lest 11.8.2020.

12. Adhikari R, Tocher J, Smith P et al. A multi-disciplinary approach to medication safety and the implication for nursing education and practice. Nurse Educ Today 2014; 34: 185-90.

[PubMed][CrossRef]

13. NOU 2015:11. Med åpne kort. Forebygging og oppfølging av alvorlige hendelser i helse- og omsorgstjenestene.

https://www.regjeringen.no/contentassets/daaed86b64co4f79a279oe87d8bb4576/no/pdfs/nou20152015 oo110oodddpdfs.pdf Lest 11.8.2020.

14. Braithwaite J, Herkes J, Ludlow K et al. Association between organisational and workplace cultures, and patient outcomes: systematic review. BMJ Open 2017; 7: eo17708. [PubMed][CrossRef]

15. Pronovost P, Sexton B. Assessing safety culture: guidelines and recommendations. Qual Saf Health Care 2005; 14: 231-3. [PubMed][CrossRef]

16. Helse Sør-Øst. ForBedring. https://www.helse-sorost.no/forbedring Lest 28.11.2020. 
17. Deilkås E, Hofoss D. Patient safety culture lives in departments and wards: multilevel partitioning of variance in patient safety culture. BMC Health Serv Res 2010; 10: 85. [PubMed][CrossRef]

18. Standard Norge. Anestesi- og respirasjonsutstyr - Brukerpåførte etiketter for sprøyter som inneholder legemidler til bruk ved anestesi - Farger, utforming og ytelse.

https://www.standard.no/no/Nettbutikk/produktkatalogen/Produktpresentasjon/?ProductID=919818 Lest 11.8.2020.

19. Kalveland J. Avdekket omfattende svikt i multidose-tilsyn. Dagens medisin 10.4.2019.

https://www.dagensmedisin.no/artikler/2019/04/10/alvorlige-avvik-i-nmd-tilsyn Lest 11.8.2020.

20. Grimsmo A. Elektronisk resept-uten bivirkninger? Tidsskr Nor Lægeforen 2006; 126:1740-3. [PubMed]

21. Helsedirektoratet. Nasjonale anbefalinger, råd og pakkeforløp: Læringsnotat. https://www.helsedirektoratet.no/produkter?temalaeringsnotat Lest 11.8.2020.

Publisert: 16. mars 2021. Tidsskr Nor Legeforen. DOI: 10.4045/tidsskr.20.0664

Mottatt 20.8.2020, første revisjon innsendt 5.11.2020, godkjent 13.1.2021.

(C) Tidsskrift for Den norske legeforening 2020. Lastet ned fra tidsskriftet.no 